\title{
PROGRESS REPORTS
}

\section{Skin and gullet}

\author{
S Walton, J R Bennett
}

Diseases of the skin and gullet coexist more often than would be expected by chance, though perhaps no more than one might expect considering the ectodermal origin of the oesophageal mucosa. Several types of interaction betwen the skin and the oesophagus are possible:

(1) The skin disease is the cause of oesophageal disease;

(2) The skin and oesophageal disease have a common pathology;

(3) The two are indirectly related as in the genetic orocutaneous syndromes.

Identification of the relation is important, both for understanding and clinical management, although some cutaneo-oesophageal relations cannot, at present, be categorised into these groups as our knowledge is insufficient.

This review will deal with changes in the skin that are associated with disease in the oesophagus, contributing to the common symptom triad of dysphagia/heartburn/acid regurgitation.

\section{Oro-oculo-genito-cutaneous syndromes}

\section{(1) BEHCET'S DISEASE}

The diagnosis of this heterogeneous disease depends on the identification of its more typical clinical features. The recently revised diagnostic criteria ${ }^{1}$ include recurrent oral ulceration and two of the following: recurrent genital ulcers, eye involvement (uveitis or vasculitis), skin manifestations (erythema nodosusm or papulopustular/acneiform lesions), and a positive pathergy test.

Oesophageal involvement is rare. Erosions, perforated ulcers, widely spreading oesophagitis, and severe stenosis have been described. ${ }^{2}$ There is no specific treatment and steroids are of limited value. Our own experience suggests that colchicine is useful in patients with oral, genital, and ocular disease. ${ }^{3}$ Treatment has to be individually tailored to the patient rather than standardised for all patients.

Departments of Dermatology and Gastroenterology, Hull

Royal Infirmary, Hull

S Walton

J R Bennett

Correspondence to:

Dr J R Bennett, Hull Royal

Infirmary, Anlaby Road, Hull

HU3 2JZ.

Accepted for publication

17 August 1990
In Stevens-Johnson syndrome (the bullouserosive variant of erythema multiforme) dysphagia may result from ulceration of buccal, pharyngeal, and oesophageal mucosae. Very rarely, bullae and eosinophilic necrosis of the oesophagus have been described. ${ }^{4}$ Treatment is usually symptomatic, although severe cases may need hospital admission for steroid treatment and maintenance of fluid intake. If possible, the aetiological agent should be identified and dealt with appropriately.

\section{(3) ACQUIRED IMMUNODEFICIENCY SYNDROME (AIDS)}

This syndrome was first reported in male homosexuals in the United States in 1981. Severe opportunistic infections and uncommon malignancies occur against a background of profound $T$ cell immunosuppression in a previously healthy adult.

Oesophageal and dermatologic manifestations of AIDS are secondary to the severe $T$ cell immunodeficiency and, in most instances, can be related to the presence of opportunistic infection. Chronic candidal infection of the mucous membranes may result in erosive oesophagitis. ${ }^{5}$ Herpes simplex and cytomegaloviruses have produced oesophageal ulcers ${ }^{67}$ and oesophagitis, ${ }^{89}$ both in immunocompetent homosexual men and patients infected with the human immunodeficiency virus, HIV. Kaposi's sarcoma can occur on the skin or mucous membranes.

Topical treatment is ineffective for oesophageal candida, and systemic antifungal agents are usually required. There is little to choose between the new expensive triazole, fluconazole, and the imidazole, ketoconazole. Intravenous foscarnet heals cytomegalovirus ulceration of the oesophagus with long term remission of symptoms for up to six months. Ganciclovir is also effective but may produce granulocytopaenia. Acyclovir is used for the treatment of herpetic oesophagitis and the ulceration/leucoplakia caused by infection with Epstein-Barr virus or papilloma virus. ${ }^{10}$

\section{Bullous disorders}

\section{(1) PEMPHIGUS VULGARIS}

This is the most serious of the bullous diseases and was often fatal before systemic corticosteroid treatments were available. Blisters are widespread and occur within the epidermis. Mucosae are often affected, although blisters break easily and erosions are the main physical sign in the mouth. Extensive use of endoscopic fibreoptic techniques has shown that oesophageal involvement of pemphigus vulgaris is not as rare as previously thought. The various oesophageal changes described include the presence of erosions, bullae, ${ }^{11}$ and a condition called 'oesophagitis dissecans superficialis' in which the patient vomits a cast of the oesophageal mucosa. ${ }^{12}$ 
A histological and immunofluorescent diagnosis is mandatory as oesophageal involvement may necessitate a higher dose of steroids. " Candida, herpetic oesophagitis, and peptic disease, which are frequent in steroid treated patients, should be excluded and appropriately treated. As in the skin, the histological findings of acantholysis (separation of epidermal cells) is associated with the deposition of immunoglobulin, IgG, antibodies and occasionally complement, $\mathrm{C}_{3}$ between epidermal cells.

The mainstay of treatment ${ }^{13}$ is systemic corticosteroids and immunosuppressive drugs. Rarely, plasma exchange, ${ }^{14}$ chrysotherapy ${ }^{15}$ and possibly inorganic arsenic also have a place. Gold should be reserved for those patients who either fail to respond to steroids and immunosuppression or who cannot tolerate these drugs. ${ }^{16}$

\section{(2) PEMPHIGOID}

Blisters, usually widespread, occur at subepidermal level in bullous pemphigoid - a blistering skin disease of the elderly. Although it may last for life, it is more likely to go into spontaneous remission than pemphigus. Mouth and other mucosal lesions occur in bullous pemphigoid but are less common than in pemphigus and mucous membrane pemphigoid, a distinct variant of pemphigoid, in which mucous membrane lesions may be the presenting feature and may occur without skin blisters. Confirmation of the diagnosis can be obtained by the finding of a continuous band of immunoglobulin (IgG) and complement $\left(\mathrm{C}_{4}\right)$ at the dermoepidermal junction. Oesophageal involvement is rare and has been reported to include bullae, diffuse oesophagitis, adhesions, webs, and strictures. ${ }^{17} \mathrm{Com}$ plications have included gastrointestinal haemorrhage ${ }^{18}$ and sloughing off of the entire oesophageal mucosa as a hollow membraneous cast. ${ }^{19}$ Although pemphigoid is now not thought to be statistically associated with malignancy, ${ }^{20}$ there is one report of its occurring concurrently with oesophageal carcinoma. ${ }^{21}$ The treatment of bullous pemphigoid is similar to that of pemphigus vulgaris, with corticosteroid and immunosuppressive drugs, especially azathioprine.

\section{(3) EPIDERMOLYSIS BULLOSA (EB)}

Oesophageal disease becomes symptomatic at any age and most reported series include patients between infancy and the third decade. ${ }^{22}$ The types of oesophageal involvement vary - mucosal bullae can be precipitated by the ingestion of coarse food, causing dysphagia and sometimes obstruction of the oesophagus leading to regurgitation of food and bloodstained secretions; oesophageal web formation is a recognised complication of dystrophic EB, due to localised mucosal damage by blistering but it may also be related to the chronic iron deficiency in EB caused by blood loss from the skin and gut coupled with inadequate dietary intake; ${ }^{23}$ oesophageal strictures pose a major problem with about half occurring in the proximal oesophagus, a quarter in the lower oesophagus, and the remainder occurring at multiple sites; gastro- oesophageal reflux and hiatus hernia have been observed in the recessive dystrophic variant of EB, contributing to lower oesophageal ulceration and stricture formation. Disordered or poor oesophageal peristalsis has also been observed during radiological examination.

Autosomal recessive dystrophic EB is most frequently associated with extensive lesions of the oesophagus and other mucous membranes. The autosomal dominant form of the disease occasionally results in moderately severe bullous skin lesions and can be associated with oral, oesophageal, and anal blistering, although severe erosions and strictures are not a feature. Junctional EB, an autosomal recessive disorder with extensive skin blistering and considerable neonatal mortality, can be associated with oral, oesophageal, and anal blisters. The oesophagus is not usually affected in acquired EB (EB acquisita).

There is no definite treatment for the oesophageal lesions of EB, Treatment in the acute stage is, therefore, symptomatic and aimed at decreasing bullae formation, preventing aspiration of food and secretions, and maintaining nutrition with hyperalimentation. High dose steroids for short periods are sometimes effective in relieving dysphagia. Phenytoin is mostly effective in the treatment of skin lesions but has benefited some patients with oesophageal involvement. The cervical strictures are easily dilated but diffuse oesophageal involvement is more difficult to manage with a considerable risk of perforation from the procedure. Surgical treatment for oesophageal stricture is indicated when the lesion is no longer responsive to dilatation or if perforation or further strictures occur because of dilatation. Provided adequate perioperative attention is given to the patients' nutrition, skin bullae, and ulceration, colonic interposition either to bypass or replace the strictured oesophageal segment, has been reported with success. ${ }^{24}$

\section{Hyperkeratotic disorders}

\section{(1) DIFFUSE PALMOPLANTAR KERATODERMA (TYLOSIS)}

Howel-Evans et $a l^{25}$ first reported the association of dominantly inherited tylosis, with carcinoma of the oesophagus in 48 members of two families in Liverpool, who developed tylosis of the late onset type, 17 of whom developed squamous oesophageal carcinoma. Since then, various cases of a similar association have been reported. One study describing 22 members of a south Indian family, spanning five generations, makes the point that squamous cell carcinoma may also develop in the tylotic skin. ${ }^{26}$

\section{(2) ACANTHOSIS NIGRICANS}

The skin in this condition is described as warty, thickened, and pigmented - changes are most noticeable in the flexures but can affect any area of the body including mucous membranes. Endoscopy on one occasion showed a warty oesophageal surface caused by mucosal thickening. ${ }^{27}$ 
There is suggestion of a circulating epidermotrophic growth factor in acanthosis nigricans that is similar in structure to urogastrone, and this is particularly interesting in view of the predominance of gastric cancers in this condition.

(3) DARIER'S DISEASE (KERATOSIS FOLLICULARIS) ${ }^{28}$ This condition is determined by an autosomal dominant gene with variable penetrance. The distinctive skin lesion is a firm, greasy, crusted papule, the colour varying from skin coloured to yellowish brown. Coalescence of these papules produces irregular warty plaques or papillomatous masses affecting the seborrhoeic areas of the face and trunk. On the palms and soles there may be punctate keratoses or minute pits which are pathognomonic. The nails show longitudinal ridging with a $\mathrm{V}$ shaped nick at the free margin.

Lesions of the mucous membranes are uncommon and white umbilicate or 'cobblestone' papules on the tongue, oropharynx, oesophagus, rectum, and vulva may be associated with gingival hypertrophy. Confluence of the papules may simulate leukoplakia.

Most patients with Darier's disease become symptomatic by the third decade, though the disease can start at the age of 10 years. The diagnosis is essentially clinical, though distinctive histological changes in the skin include suprabasal lacunae, epidermal dyskeratosis with the formation of 'corps ronds' and 'grains', and a variable degree of hyperkeratosis, parakeratosis and acanthosis.

Treatment of the skin is largely symptomatic with the use of simple emollients or aromatic retinoids for severe disease. No specific therapy is known to help mucosal lesions.

\section{(4) LICHEN PLANUS}

The cause of lichen planus remains unknown. The characteristic skin lesion is a tiny, flat topped, shiny, violaceous papule, often seen with a network of delicate white lines on its surface known as Wickham's striae. Lesions are usually distributed symmetrically and bilaterally over flexor surfaces of the forearms and wrists, neck, legs, and lower back. Oral mucous membranes and genitalia are also affected. Healing sites may show striking hyperpigmentation. Histologically, the papule of lichen planus shows thickening of granular layer, liquefaction degeneration of basal layer, and a band like lymphohistiocytic infiltrate in the upper dermis. Pigmentary incontinence and 'Civatte bodies' may be seen in the dermis.

Oesophageal disease may result in dysphagia and the formation of benign strictures. The prevalence of oesophageal disease has been greatly underestimated in the past. In our most recent endoscopic study, we found that a quarter of patients with lichen planus had oesophageal involvement in the form of papular lesions, though severe erosive changes were rare. ${ }^{29}$ In view of the increased risk of malignant change with oral lichen planus, ${ }^{30} \mathrm{chronic}$ erosive changes of lichen planus in the oesophagus may also be premalignant, although no such cases have been reported. When severe oesophageal disease is found, steroid treatment should be started to reduce the symptoms and any strictures and possibly to decrease any risk of malignant transformation. ${ }^{3031}$

\section{Collagen vascular diseases}

\section{(1) SYSTEMIC SCLEROSIS}

The cutaneous changes ${ }^{32}$ affect the face and hands most frequently, though the changes may extend to affect the skin generally. The facial appearance is characteristic. Small mat like telangiectasia are frequently found on the face and hands - the hands and fingers being swollen and tumid in early disease, evolving into atrophic changes as the disease progresses. Small painful ulcers on the fingers heal leaving depressed scars and are sometimes associated with gangrenous changes and discharge of calcium deposits from time to time. Other skin changes include generalised pigmentation resmbling Addison's disease, slow healing leg ulcers, livedo reticularis, and small white areas of atrophie blanche.

Oesophageal motility is shown to be abnormal by radiology in about $66 \%$ but manometric changes are found in up to $85 \%$ of patients. Manometric abnormalities include absent peristalsis of the smooth muscle oesophagus and a reduced lower oesophageal sphincter pressure. The upper oesophageal sphincter pressure is normal and peristalsis may be preserved in the upper 4 to $5 \mathrm{~cm} .{ }^{33}$ The main oesophageal symptoms are of gastro-oesophageal reflux and dysphagia, suggesting the development of a stricture. However, a third of affected patients have no oesophageal symptoms. Strictures occur in approximately $10 \%$ of patients and carcinoma of the oesophagus has been reported..$^{32}$

\section{(2) DERMATOMYOSITIS}

The rash in well developed cases is diagnostic. Purplish red heliotrope oedema affects the upper half of the face, mainly the eyelids, but may also be found on the hands and other areas of the body. Scaly, bluish red plaques on the back of the fingers, especially over the knuckles, are sometimes seen as dilated and tortuous nail fold capillary loops. Ragged cuticles, as in other collagen vascular diseases, are sometimes a feature.

Dysphagia is a prominent symptom attributed to involvement of the muscles of the pharynx and oesophagus in a fashion similar to involvement of proximal skeletal muscles. Diverticular outpouching of the oesophagus can develop as a result of the muscle weakness. ${ }^{32}$ Regardless of whether there is an underlying neoplasm, a myopathy, especially when it involves muscles of swallowing, is an indication for urgent treatment with adequate doses of systemic corticosteroids and sometimes azathioprine as well.

1 International Study Group For Behçet's Disease. Criteria for
diagnosis of Behçet's disease. Lancet 1990; 335: 1078-80.
2 Mori S, Yoshihira A, Kawamura H, et al. Esophageal involve-
ment in Behçet's disease. Am F Gastroenterol 1983; 78: 548- 
3 Muzulu SI, Walton S, Keczkes K. Colchicine therapy in Behcet's syndrome - a report of 5 cases. Clin Exp Dermatol $1989 ; 14: 298-9$.

4 Heer M, Altorfer J, Burger H, et al. Bullous esophageal lesions due to cotrimoxazole: an immune-mediated process? Gastroenterology 1985; 88: 1954-7.

5 Ammann AJ, Cutaneous manifestations of immunodeficiency disorders. In: Fitzpatrick TB, Eisen AZ, Wolff K, Freedberg IM, Austen KF, eds. Dermatology in general medicine (3rd ed). New York: McGraw-Hill Book Company, 1987: 2517-9.

6 St Onge G, Bezahler GH. Giant esophageal ulcer associated with cytomegalovirus. Gastroenterology 1982; 83: 127-30.

7 Rabeneck L, Boyko WJ, McLean DM, et al. Unusual esophageal ulcers containing enveloped virus like particles in homosexual men. Gastroenterology 1986; 90: 1882-9.

8 Solammadevi SV, Patwardhan R. Herpes esophagitis. Am $\mathcal{f}$ Gastroenterol 1982; 77: 48-50.

9 Villar LA, Massanari RM, Mitros FA. Cytomegalovirus infection with acute erosive esophagitis. Am $\mathscr{F}$ Med 1984; 76: 924-8.

10 Gazzard BG. Practical advice for the gastroenterologist dealing with symptomatic HIV disease. Gut 1990; 31: 733-5.

11 Goldin E, Lijovetzky G. Esophageal involvement by pemphigus vulgaris. Am f Gastroenterol 1985; 80: 828-30.

12 Kaplan RP, Touloukian J, Ahmed AR, et al. Esophagitis dissecans superficialis associated with pemphigus vulgaris. f Am Acad Dermatol 1981; 4: 682-7.

13 Walton S, Marks J. Bullous eruptions: advances in understanding and treatment. Update 1985; 30: 1263-7.

14 Walton S, Keczkes K, Robinson AE. A case of penicillamineinduced pemphigus successfully treated by plasma induced pemphigus successfully treated

15 Walton S, Keczkes K. Pemphigus foliaceous - successful treatment with adjuvant gold therapy. Clin Exp Dermatol 1987; 12: 364-5.

16 Pye RJ. Bullous eruptions. In: Rook A, Wilkinson DS, Ebling FJG, Champion RH, Burton JL, eds. Textbook of dermatology (4th ed). Oxford: Blackwell Scientific Publications, 1986: 1637.

17 Agha FP, Raji MR. Esophageal involvement in pemphigoid. Gastrointest Radiol 1982; 7: 109-12.

18 Eng TY, Hogan WJ, Jordan RE. Oesophageal involvement in bullous pemphigoid: a possible cause of gastrointestinal bullous pemphigoid: a possible cause of gast
haemorrhage. Br f Dermatol 1978; 99: 207-10.
19 Foroozan P, Enta T, Winship D, et al. Loss and regeneration of the esophageal mucosa in pemphigoid. Gastroenterology 1967; 52: 548-58.

20 Lindelöf B, Islam N, Eklund G, et al. Pemphigoid and cancer. Arch Dermatol 1990; 126: 66-8.

21 Furukawa F, Ozaki M, Imamura S, et al. Bullous pemphigoid associated with radiotherapy for esophageal carcinoma. Dermatologica $1981 ; 162: 451-4$.

22 Gryboski JD, Touloukian R, Campanella RA. Gastrointestinal manifestations of epidermolysis bullosa in children. Arch Dermatol 1988; 124: 746-52.

23 Tidman MJ, Martin IR, Wells RS, et al. Oesophageal web formation in dystrophic epidermolysis bullosa. Clin Exp Dermatol 1988; 13: 279-81.

24 Touloukian RJ, Schonholz SM, Gryboski JD, et al. Perioperative considerations in esophageal replacement for epidermolysis bullosa: report of two cases successfully treated with moly int

25 Howel-Evans W, McConnell RB, Clarke CA, et al. Carcinoma of the oesophagus with keratosis palmaris et plantaris of the oesophagus with keratosis
(tylosis). Qf Med 1958; 27: 413-29.

26 Yesudian P, Premalatha S, Thambiah AS. Genetic tylosis with malignancy: a study of a south Indian pedigree. $\mathrm{Br} \mathcal{J}$ Dermatol 1980; 102: 597-600.

27 Walton S, Krause L, Marks J. A case of acanthosis nigricans an investigative approach. Clin Exp Dermatol 1984; 9: 58-63.

28 Wilkinson JD, Darier's Disease. In: Rook A, Wilkinson DS, Ebling FJG, Champion RH, Burton JL, eds. Textbook of dermatology (4th ed). Oxford: Blackwell Scientific Publications, 1986: 1439-43.

29 Dickens CM, Heseltine D, Walton S, et al. The oesophagus in lichen planus: an endoscopic study. $B M \mathcal{F}$ 1990; 300: 84.

30 Jobard-Drobacheff C, Blae D, Quencez E, et al. Lichen planus of the oesophagus. Clin Exp Dermatol 1988; 13: 38-41.

31 Sheehan-Dare RA, Cotterill JA, Simmons AV. Oesophageal lichen planus. BrF Dermatol 1986; 115: 729-30.

32 Rowell NR. Lupus erythematosus, scleroderma and dermatomyositis: the 'collagen' or 'connective-tissue' diseases. In: Rook A, Wilkinson DS, Ebling FJG, Champion RH, Burton JL (eds). Textbook of dermatology (4th ed). Oxford: Blackwell Scientific Publications, 1986: 1352-6.

33 Weihrauch TR, Korting GW. Manometric assessment of oesophageal involvement in progressive systemic sclerosis, morphoea and Raynaud's disease. Br F Dermatol 1982; 107: 325-32. 